\title{
Globe
}

Revue internationale d'études québécoises

Lucie Piché : Femmes et changement social au Québec. L'apport de la jeunesse ouvrière catholique féminine, 1931-1966. Québec, Presses de l’Université Laval, 2003

\section{Élise Jacob}

Volume 8, numéro 2, 2005

URI : https://id.erudit.org/iderudit/1000919ar

DOI : https://doi.org/10.7202/1000919ar

Aller au sommaire du numéro

Éditeur(s)

Globe, Revue internationale d'études québécoises

ISSN

1481-5869 (imprimé)

1923-8231 (numérique)

Découvrir la revue

Citer ce compte rendu

Jacob, É. (2005). Compte rendu de [Lucie Piché : Femmes et changement social au Québec. L'apport de la jeunesse ouvrière catholique féminine, 1931-1966.

Québec, Presses de l'Université Laval, 2003]. Globe, 8(2), 302-304.

https://doi.org/10.7202/1000919ar d'utilisation que vous pouvez consulter en ligne.

https://apropos.erudit.org/fr/usagers/politique-dutilisation/ 
la pensée de certains personnages réels, et les idées qu'il cherche à nous faire comprendre sont incarnées par des hommes immergés dans un présent contingent. Harvey ne se perd pas pour autant dans les détails biographiques ou les anecdotes futiles. Enfin, son hypothèse de départ me semble la mieux fondée sur le plan des sources, la plus crédible au final. Son recours aux archives d'époque n'est cependant pas un étalage vain d'érudition. Les fonds privés, les brochures et les documents d'époque qu'il cite éclairent de façon souvent pénétrante son point de vue. Il y là un vrai travail monographique qui fournit au lecteur des conclusions probablement plus durables.

Éric Bédard

Télé-université - Université du Québec à Montréal

\section{Lucie Piché}

Femmes et changement social au Québec. L'apport de la jeunesse ouvrière catbolique féminine, 1931-1966. Québec, Presses de l'Université Laval, 2003.

S'ils renvoient aujourd'hui bien souvent à un conservatisme idéologique, les mouvements catholiques peuvent néanmoins participer à certaines transformations sociales, voire se révéler progressistes (allant parfois même jusqu'au radicalisme révolutionnaire de la théologie de la libération). À ce titre, Femmes et changement social se montre éclairant en portant un regard précis sur un aspect encore peu étudié d'une époque charnière de l'histoire du Québec : l'influence de la Jeunesse ouvrière catholique féminine (JOCF) sur les jeunes femmes issues de la classe ouvrière, dans le deuxième tiers du $x^{e}$ siècle. S'inscrivant dans la foulée de plusieurs autres travaux ayant trait à la jeunesse - pensons notamment à ceux de Louise Bienvenue (Quand la jeunesse entre en scène, Boréal, 2003) -, l'ouvrage constitue la première étude spécifiquement consacrée aux branches féminines des mouvements catholiques. Historienne et chercheure associée à l'Observatoire Jeunes et Société de l'Institut national de la recherche scientifique, Lucie Piché soutient que la JOCF a contribué - à la formation d'une élite féminine issue des milieux populaires " (p. 304). Plus encore, l'organisation aurait permis à ses membres d'accéder à la sphère publique québécoise par le biais d'un engagement social concret. 
Divisé en six chapitres, l'ouvrage aborde les apports de la JOCF, qui se situent au carrefour de problématiques liées à la jeunesse, à la condition féminine et à la religion catholique. L'auteure dresse d'abord le portrait des différentes associations pour la jeunesse et pour les femmes au Québec dans la première moitié du $\mathrm{xx}^{\mathrm{e}}$ siècle. Dans une perspective plutôt sociologique, elle met en évidence le développement des nouvelles conceptions de la jeunesse comme catégorie sociale et souligne l'isolement et la marginalisation des femmes sur la scène sociopolitique, qui semblent expliquer la popularité des mouvements pour les jeunes dans les années 1930. Le deuxième chapitre expose l'origine et la ligne de pensée de la JOCF, centrée sur une philosophie de l'action et résumée par la formule "Voir-Juger-Agir *. L'originalité du mouvement réside d'ailleurs dans son approche et ses valeurs : il prône l'importance d'un engagement laïque, la prise en charge par les pairs, l'apprentissage par l'enquête et l'action dans le milieu.

Le chapitre suivant met en lumière l'évolution des effectifs et le profil des membres du mouvement. Dès sa formation en 1932, la JOCF prédomine dans les régions, Montréal semblant déserter rapidement l'organisation. Bien que la JOCF soit marquée par une implantation rapide, le nombre des jocistes de même que la durée de leur adhésion ne cessent de diminuer au cours des années. Par conséquent, elle ne devient qu'un lieu de passage pour plusieurs jeunes femmes. Lucie Piché souligne en ce sens que "si la JOCF ne réussit pas à devenir un mouvement de masse, elle parvient néanmoins à recruter des jeunes travailleuses issues de cette masse. (p. 130). Parallèlement à la promotion d'un militantisme catholique laïque, qui conduira à une certaine autonomie vis-à-vis de l'Église et imprégnera une partie de la Révolution tranquille, l'attachement de l'organisation au conservatisme moral et social peut expliquer le désinvestissement des jocistes. C'est pourquoi le mouvement n'a d'autre avenue que de réviser ses positions à partir des années 1940, tel que l'illustre le quatrième chapitre en rendant compte de l'itinéraire idéologique de la JOCF, qui passe du corporatisme au socialisme démocratique. Dès lors que la doctrine religieuse s'éloigne de la réalité des jeunes et que l'écart entre les structures centralisatrices du pouvoir (évêques et curés) et les cellules de base (paroisses) croît de manière inexorable, l'organisation peine à évoluer dans ce climat de crise, l'Église tentant constamment de freiner son mouvement. 
À cet égard, le cinquième chapitre met au jour une analyse concrète du discours préconisé par la direction de la JOCF. Avant 1950, l'attitude de cette dernière demeure tributaire du moralisme chrétien, qui réduit la conception de la femme au déterminisme biologique, envisageant sa réalité strictement sous l'angle de la maternité. Le regroupement, dès 1940 , revendique néanmoins l'égalité des droits des femmes au travail et s'associe à un militantisme syndical. Malgré la prescription de certains diktats, la JOCF représente pour les jeunes femmes l'unique espace de socialisation possible et la seule véritable façon d'accéder à la sphère publique. C'est par le biais de l'analyse de plusieurs documents produits par le mouvement que Lucie Piché est en mesure d'observer, au sixième chapitre, l'impact de la formation éducative et religieuse reçue par les jocistes. L'auteure stipule ainsi que les jeunes travailleuses " ont accès [...] à une association confessionnelle qui leur offre des cours, des services et leur permet, si elles le désirent, de s'engager à fond dans l'apostolat social " (p. 297). La remise en cause des normes établies est notamment tangible dans cette dernière partie, qui relate les tensions non seulement au sein du mouvement, mais également entre les jocistes et leur milieu familial. Davantage centrée sur les trajectoires individuelles que les chapitres précédents, l'analyse aurait gagné ici à être étayée de témoignages personnels.

Quoiqu'il vise avant tout à souligner la contribution de la JOCF à la dynamique sociale du Québec, l'ouvrage se présente comme une étude objective et nuancée, qui expose également les limites du mouvement. Alors que la direction de l'organisation plaide pour l'engagement social des femmes, elle considère également que celui-ci doit se fonder " essentiellement sur la base de la complémentarité des rôles et de leurs fonctions " (p. 234). Les revendications, principalement liées à la sphère du travail, ne se font donc qu'à travers le prisme de la différence sexuelle. De fait, la JOCF ne permet aucunement de remettre en question les rôles sociosexués, qui restent au cœur des problématiques auxquelles sont confrontées les jeunes femmes issues des milieux populaires. Si les études féministes auraient probablement fait une lecture différente des impacts du mouvement, la neutralité et la rigueur de la recherche contribuent à la portée de cette étude significative pour l'histoire de la jeunesse québécoise. 